\title{
Projected Reduction in Healthcare Costs in Belgium After Optimization of lodine Intake: Impact on Costs Related to Thyroid Nodular Disease
}

\author{
Stefanie Vandevijvere, Lieven Annemans, ${ }^{2}$ Herman Van Oyen, ${ }^{1}$ \\ Jean Tafforeau, and Rodrigo Moreno-Reyes ${ }^{3}$
}

Background: Several surveys in the last 50 years have repeatedly indicated that Belgium is affected by mild iodine deficiency. Within the framework of the national food and health plan in Belgium, a selective, progressive, and monitored strategy was proposed in 2009 to optimize iodine intake. The objective of the present study was to perform a health economic evaluation of the consequences of inadequate iodine intake in Belgium, focusing on undisputed and measurable health outcomes such as thyroid nodular disease and its associated morbidity (hyperthyroidism).

Methods: For the estimation of direct, indirect, medical, and nonmedical costs related to thyroid nodular diseases in Belgium, data from the Federal Public Service of Public Health, Food Chain Safety and Environment, the National Institute for Disease and Disability Insurance (RIZIV/INAMI), the Information Network about the prescription of reimbursable medicines (FARMANET), Intercontinental Marketing Services, and expert opinions were used. These costs translate into savings after implementation of the iodization program and are defined as costs due to thyroid nodular disease throughout the article. Costs related to the iodization program are referred to as program costs. Only figures dating from before the start of the intervention were exploited. Only adult and elderly people ( $\geq 18$ years) were taken into account in this study because thyroid nodular diseases predominantly affect this age group.

Results: The yearly costs due to thyroid nodular diseases caused by mild iodine deficiency in the Belgian adult population are $\sim € 38$ million. It is expected that the iodization program will result in additional costs of $\sim € 54,000$ per year and decrease the prevalence of thyroid nodular diseases by $38 \%$ after a $4-5$-year period. The net savings after establishment of the program are therefore estimated to be at least $€ 14$ million a year.

Conclusions: Optimization of iodine intake in Belgium should be quite cost effective, if only considering its impact on nodular thyroid disease. There are likely added benefits relating to more optimal thyroid hormone influenced brain development that are more difficult to estimate but may be even more important.

\section{Introduction}

D ESPITE A WORLDWIDE successful implementation of iodine fortification and supplementation programs over the last 4 decades, iodine deficiency remains a public heath problem in Europe. In 2004, it was estimated that of the 2 billion people around the world at risk of iodine deficiency, $20 \%$ live in Europe (1). Over the last 2 decades, extraordinary progress has been achieved in decreasing the prevalence of iodine deficiency disorders by increasing the number of people with access to iodized salt (2). However, this has not been the case in Europe, where, compared to other regions in the world, iodized salt coverage is low, reaching only $27 \%$ of households (3).

Several surveys in the last 50 years have repeatedly indicated that Belgium is affected by mild iodine deficiency (MID) (4-6). In 1998, a representative survey in Belgian school children showed a median urinary iodine concentration of $80 \mu \mathrm{g} / \mathrm{L}(4)$, lower than the optimal urinary median values of $100-199 \mu \mathrm{g} / \mathrm{L}$ in the population (7). Consequently, optimizing iodine intake was chosen among several other nutritional issues as a priority by the Ministry of Health in its "National

\footnotetext{
${ }^{1}$ Unit of Epidemiology, Scientific Institute of Public Health, Brussels, Belgium.

${ }^{2}$ Department of Public Health, Ghent University, Ghent, Belgium.

${ }^{3}$ Department of Nuclear Medicine, Hôpital Erasme, Université Libre de Bruxelles, Brussels, Belgium.
} 
Nutrition and Health Plan for Belgium" for the period 20052010. Within the framework of this plan, a selective, progressive, and monitored strategy was proposed to optimize iodine intake in Belgium.

In an agreement between the bread sector and the Ministry of Health, Food Chain Safety and Environment, signed in April 2009, it was established that from then onward, all breads produced would be fortified with iodized salt (10-15 ppm). This choice stems from the fact that it is easier to control and regulate the iodine content in one food item rather than in several items. Also the implementation is easier as bread is mainly made for local consumption. A selective approach is particularly relevant in countries affected by MID like Belgium to avoid an increase of iodine beyond the optimal intake.

The fortification of bread with iodine has already been implemented with success in other countries like The Netherlands $(8)$ and Denmark $(9,10)$. To be truly selective this strategy implies that other potential sources of iodine should be avoided or at least maintained constant to avoid uncontrolled variation of iodine intake in the population.

Because a transitory increase of hyperthyroidism may occur in case of rapid increase of iodine intake, in particular in the elderly population with multinodular goiter, a progressive, step-by-step increase of iodine intake is preferred (11). This notion is particularly important because small variations in daily iodine intake are sufficient to affect thyroid function (12-14).

The results of the national food consumption survey in adults (2004) showed that the bread consumption amounts to $120 \mathrm{~g} /$ day (P25: $82 \mathrm{~g} /$ day; P75: $150 \mathrm{~g} /$ day) and is the most important source of salt intake in Belgium (15).

Considering an estimated daily iodine intake of $80 \mu \mathrm{g}$ of iodine in Belgium (4), the strategy is aiming at an initial increase in daily iodine intake of $30 \mu \mathrm{g}$ during the first 5 years. In a second phase, taking into account the results of the monitoring program, a further increase of $40 \mu \mathrm{g}$ of daily iodine intake is aimed at to attain an average intake of $150 \mu \mathrm{g}$ of iodine over a period of 10 years (16).

The drawback of a selective and progressive strategy is that some people, who only eat very little bread, don't benefit from the intervention such as weaning infants, ethnic groups, people on a weight-loss or low-carbohydrate diet, and persons with celiac disease.

Monitoring will be based on the determination of urinary iodine concentrations in a representative sample of schoolaged children and pregnant women every $4-5$ years, as well as on the evaluation of thyroid function in pregnant women and thyroid-stimulating hormone (TSH) concentrations in newborns. Data on neonatal TSH will be collected from the six reference centers performing the screening of congenital hypothyroidism in Belgium.

Further, the possible increase of any adverse effects (iodineinduced hyperthyroidism), due to the implementation of the program, will be monitored via follow-up of the use of antithyroid drugs and radio-iodine (I-131) therapy in Belgium.

Previous studies have shown that iodine fortification is both cost effective and has a high benefit/cost ratio, particularly if iodine deficiency is severe or moderate (17).

It is believed that a program for the control of MID in Belgium is worthwhile only, in health economic terms, if the societal costs of the program are lower than the saved costs that result from the correction of the deficiency.
The health economic advantages of avoiding endemic goiter and mental retardation in case of severe iodine deficiency are quite obvious. On the contrary, the benefit of correcting MID is less obvious. The main consequences of MID in the adult population are a high prevalence of multinodular goiter and thyroid nodules, which may be responsible of hyperthyroidism (18-23). In addition, it has been suggested that iodine supplementation improves cognition in mildly iodine-deficient children (24).

The objective of the present study was to perform, from the perspective of the healthcare sector (combining patient and insurer cost), a health economic evaluation of the consequences of inadequate iodine intake in Belgium, focusing on undisputed and measurable health outcomes such as nodular disease and its associated morbidity (hyperthyroidism) in the adult population. Such a health economic estimation is useful for policy makers to appraise whether the allocated resources for optimizing iodine intake in Belgium are well spent.

\section{Material and Methods}

\section{Costs due to the iodization program}

Total iodization program costs (PC) include costs of social marketing to attain public acceptance of (or preference for) the fortified food, costs of quality control and quality assurance of salt iodization in bread by producers and of governmental monitoring and evaluation activities, costs of any campaign or publication stimulating iodine supplementation, and costs of the monitoring program for a period of 4-5 years. Monitoring of TSH in newborns is free as the data are available already. The implementation of the program does not include costs of supplying iodized salt as this is already on the market, technology cost, and costs for equipment, land, labor, maintenance, and electricity. The small difference of price between iodized salt and noniodized will not affect the cost of bread production and will not increase the price of the product.

In Belgium the salt content of bread is regulated by law and monitored on regularly by the Federal Agency for Safety of the Food Chain (FASFC). From April 2009 onward, FASFC simultaneously verifies the concentration of iodine in salt used by the bakers for the manufacture of bread, by checking the label and/or product information of the iodized salt used. These concentrations as such are not analyzed.

Therefore these costs are negligible.

\section{Costs related to thyroid nodular disease in Belgium}

Costs related to thyroid nodular disease translate into savings after implementation of the iodization program and are defined as costs due to thyroid nodular disease (TC) throughout the article.

Only adult and elderly people ( $\geq 18$ years) were taken into account in this study because thyroid nodular disease predominantly affects this age group. Further, only prevention of nodular disease (multinodular goiter and thyroid nodules) and its associated morbidity (hyperthyroidism) was included in this study. Some other saved costs (due to better cognition, higher productivity, etc.) (24-28) are important too but very difficult to assess and therefore excluded, which makes the results more conservative. Hypothyroidism is excluded in this study because this pathology is mainly due to autoimmune 
diseases, which are not related to iodine deficiency. Epidemiological studies have shown that hypothyroidism is more prevalent in populations with a high iodine intake $(20,29-32)$ or in severe iodine deficiency (2). Mild-to-moderate iodine deficiency is not associated with hypothyroidism (20), although the exact association between the level of iodine intake in a population and the occurrence of hypothyroidism is not clear. Finally, costs related to work disability, including days of absence from employment, were not included in this study.

No data are available in Belgium about the true prevalence of thyroid nodular diseases (including multinodular goiter and thyroid nodules) in the adult population, as no studies were performed in the past.

Therefore, prevalence data from a country with as much as possible the same demographic characteristics, the same salt iodization history, same intervention program, and same iodine status, food consumption pattern, and hospitalization rate for iodine deficiency disorders were used.

In Denmark, iodization of salt was prohibited from 1982 until 1998, when an optional iodization of salt was initialized. This led to only a limited use of iodized salt, so from the year 2000 iodization of all household salt and salt used in the bread industry was made mandatory to a level of $13 \mathrm{ppm}$ iodine (33). Denmark prospectively evaluated the effect of 4 years of mandatory iodization of salt (13 ppm iodine) on thyroid volume in two regional areas with, respectively, mild (the northern part of Copenhagen, eastern Denmark; median urinary iodine concentration of $61 \mu \mathrm{g} / \mathrm{L}$ before mandatory for- tification) and moderate (Aalborg, western Denmark; median urinary iodine concentration of $45 \mu \mathrm{g} / \mathrm{L}$ before mandatory fortification) iodine deficiency.

Two separate cross-sectional studies were performed before $(n=4649)$ and after $(n=3570)$ the iodization. Women aged $18-22,25-30,40-45$, and $60-65$ years and men aged 60 65 years were examined. Before the iodization, $17.6 \%$ of the participants had thyroid enlargement, whereas, after the iodization, this percentage decreased to $10.9 \%$ (33). This is a relative decrease of $38 \%$.

Denmark seems to be the country where salt iodization history is best comparable with the situation in Belgium. A comparison of demographic information, hospitalization rate for thyroid disorders, and food consumption of some key products between Belgium and Denmark can be found in Table 1.

As a starting point for this study the prevalence of thyroid enlargement in Denmark in the adult population $(17.6 \%)$ before mandatory iodization was used to estimate the prevalence of thyroid disorders (multinodular goiter and thyroid nodules) in the Belgian population. Thyroid enlargement in the Danish studies was defined as a thyroid volume greater than $18 \mathrm{~mL}$ for women and $25 \mathrm{~mL}$ for men. These values correspond to the mean +3 standard deviation values in iodine-sufficient populations (33).

It could be derived that before the introduction of the salt iodization intervention in 2009 , about $1,490,892$ adult persons were suffering from multinodular goiter and thyroid nodules

Table 1. Demographic Data, Hospitalization Rate for Thyroid Disorders, and Food Consumption of Some Key Products in Denmark and Belgium

\begin{tabular}{|c|c|c|}
\hline Demographic indicators & Belgium & Denmark \\
\hline \multicolumn{3}{|l|}{ Total population } \\
\hline Males & $5,224,309$ & $2,712,666$ \\
\hline Females & $5,442,557$ & $2,763,125$ \\
\hline \multicolumn{3}{|l|}{ Total adult population } \\
\hline Males & $4,102,708$ & $2,089,836$ \\
\hline Females & $4,368,270$ & $2,170,471$ \\
\hline Women per 100 men & 104.2 & 101.9 \\
\hline \multicolumn{3}{|l|}{ Life expectancy at birth } \\
\hline Males & 77.46 & 76.26 \\
\hline Females & 83.51 & 80.70 \\
\hline \multicolumn{3}{|l|}{ Proportion of the population } \\
\hline Aged $20-39$ years & 26.0 & 25.2 \\
\hline Aged $40-59$ years & 28.4 & 27.9 \\
\hline Aged $60-79$ years & 17.9 & 18.3 \\
\hline Aged 80 years and more & 4.7 & 4.1 \\
\hline Crude rate of net migration & 4.86 & 5.32 \\
\hline Crude birth rate & 11.67 & 11.84 \\
\hline Crude death rate & 9.49 & 9.94 \\
\hline \multicolumn{3}{|l|}{ Food consumption } \\
\hline Consumption of fish and seafood & $24 \pm 25$ g/day & $18 \pm 19$ g/day \\
\hline Consumption of dairy (products) & $203 \pm 188 \mathrm{~g} /$ day & $386 \pm 283 \mathrm{~g} /$ day \\
\hline Used dietary assessment method & $2 \times 24$-hour recall & 7-day record \\
\hline \multicolumn{3}{|l|}{ Hospitalization rate } \\
\hline $\begin{array}{l}\text { Number of hospitalizations per } 100,000 \\
\text { (whole population 2006) }\end{array}$ & 17,770 & 21,666 \\
\hline $\begin{array}{l}\text { Number of hospitalizations for thyroid } \\
\text { disorders per } 100,000 \text { (adult population 2006) }\end{array}$ & 70.5 & 58.7 \\
\hline
\end{tabular}

Sources: EUROSTAT 2008, Federal Public Service of Health in Belgium, Stat Bank in Denmark, and EFSA Concise Database, 2008. 
in Belgium. After a 4-5-year period of the intervention being in place, it is assumed that this number will decrease by about $38 \%$ to 924,353 adult persons with multinodular goiter and thyroid nodules, as was the case in Denmark.

For the estimation of direct, indirect, medical, and nonmedical TC in the adult population in Belgium, data from the Federal Public Service of Public Health, Food Chain Safety and Environment, the National Institute for Disease and Disability Insurance (RIZIV/INAMI), the Information Network about the prescription of reimbursable medicines (FARMANET), Intercontinental Marketing Services (IMS), and expert opinions were used. Only figures dating from before the start of the intervention (before 2009) were exploited.

To determine the percentage of persons undergoing surgery for multinodular goiter and thyroid nodules, data from the Federal Public Service of Health, Food Chain Safety and Environment were used. These include data from all seven insurance companies in Belgium and the public center for social welfare (OCMW). To calculate the costs of surgery and related costs (hospital stays), these data were linked with the data from RIZIV/INAMI, which include only data from all seven insurance companies in Belgium (excluding OCMW and insurance for invalid persons).

The number of adult persons ( $\geq 18$ years) undergoing surgery for multinodular goiter or thyroid nodules in Belgium was 4856 in 2003, 4925 in 2004, 4794 in 2005, 4814 in 2006, and 4973 in 2007, which resulted in a mean of 4873 per year or more or less $0.33 \%$ of the Belgian adult population suffering from thyroid nodular diseases. Only hospitalizations including thyroid nodular diseases as principal diagnosis were taken into account. Costs for surgery per year, over the years 2005-2007, including hospital stays, blood tests, metabolic therapy, pharmaceuticals, diagnosis, and clinical biology can be found in Table 2. The total average cost per year related to surgery for thyroid nodular diseases was estimated to be $€ 13,128,807$.

To assess the percentage of people with multinodular goiter or thyroid nodules going to the general practitioner or the specialist in the hospital, data about the number of adult persons ( $\geq 18$ years) using antithyroid medications (both reimbursed [FARMANET] and not reimbursed [IMS data] medication) and data about the number of persons undergoing I-131 treatment (RIZIV/INAMI) in the hospital were used.

Hormone treatment (such as with levothyroxine) is used mainly to treat hypothyroidism in Belgium. It is used much less frequently for multinodular goiter or thyroid nodules. Therefore data relating to this were not used in the analysis. In
2008 there were 20,313 adults ( $\geq 18$ years) in Belgium who were reimbursed for the use of antithyroid medications $(58,196$ packages of methimazole as thiamazol or Struma$\left.\mathrm{zol}^{\circledR}\right)$. In addition, 45,436 packages of propylthiouracil (PTU) were used by adults in the same year and it was estimated that the average number of packages per person per year was 18 . This medication is not reimbursed by the RIZIV/INAMI. The prevalence of hyperthyroidism due to Graves' disease in Denmark was $\sim 40 \%$, whereas the prevalence of hyperthyroidism due to multinodular goiter was 50\% (34). Therefore, it is estimated that $50 \%$ of the packages of methimazole and $50 \%$ of the packages of propylthiouracil were used to treat hyperthyroidism secondary to multinodular goiter or autonomous thyroid nodules in Belgium. Based on the number of packages of methimazole (either generic or brand name) whose cost was reimbursed in Belgium in 2008, the costs of these were estimated to be $€ 320,228$. Therefore, considering that half of the use of this drug was for thyrotoxic nodular thyroid disease, the reimbursement for the use of methimazole to treat thyrotoxic nodular thyroid disease was estimated to be $€ 160,114$.

I-131 therapy is widely used for the treatment of hyperthyroidism due to autonomous thyroid nodules and multinodular goiter in Belgium. It is used much less frequently for treatment of thyroid cancer and Graves' disease. The mean number of treatments with I-131 over the years 2003-2007 was 4300 , with an average total cost per year of $€ 979,537$.

In addition to treatment costs, there are costs for the diagnosis and follow-up of multinodular goiter and thyroid nodules. The only available data are those for diagnosis and follow-up by specialists. General practitioners also follow patients with nodular thyroid diseases, but blood tests and other tests for diagnosis of thyroid diseases (ultrasound, thyroid scan, and thyroid uptake) are exclusively performed by specialists. Costs related to diagnosis and follow-up by specialists were received from RIZIV/INAMI. The average number of cases and the total related average costs of diagnosis and follow-up in a hospital setting for the period 20032007 are presented in Table 3. The total average cost per year related to diagnosis and follow-up by specialists of the abovementioned pathologies was estimated to be $€ 23,267,693$.

\section{Results}

The total annual TC caused by MID in the adult population in Belgium, including surgery $(€ 13,128,807)$, diagnosis and follow-up $(23,267,693)$, medicines and hormone treatment $(€ 160,114)$, and I-131 treatment $(€ 979,537)$ amounted to $€ 37,536,151$. The total PC in Belgium, including monitoring

Table 2. Costs in Euros for Surgery Due to Thyroid Nodular Diseases in Belgium 2005-2007

\begin{tabular}{lccccc}
\hline Year & $\begin{array}{c}\text { Number of } \\
\text { hospital stays }\end{array}$ & $\begin{array}{c}\text { Number of } \\
\text { hospital days }\end{array}$ & $A$ & B & Total costs \\
\hline 2005 & 4712 & 20,785 & $€ 6,321,419$ & $€ 6,088,117$ & $€ 12,409,536$ \\
2006 & 4770 & 20,255 & $€ 6,490,184$ & $€ 6,531,599$ & $€ 13,021,783$ \\
2007 & 4946 & 20,199 & $€ 6,762,609$ & $€ 7,192,494$ & $€ 13,955,103$ \\
Av/Y & 4809 & 20,413 & $€ 6,524,737$ & $€ 6,604,070$ & $€ 13,128,807$ \\
\hline
\end{tabular}

$\mathrm{Av} / \mathrm{Y}$, average costs per year; A, costs related to stays in the hospital; B, costs related to blood tests, metabolic therapy, use of pharmaceuticals, diagnosis tests, and clinical biology.

Source: Link between Data Federal Public Service of Health and RIZIV/INAMI. 
Table 3. Average Yearly Costs in Euros of Diagnosis and Follow-Up of Thyroid Nodular Diseases by Specialists in Belgium 2003-2007

\begin{tabular}{lcr}
\hline Test & $\begin{array}{c}\text { Average number } \\
\text { of cases }\end{array}$ & \multicolumn{1}{c}{$\begin{array}{c}\text { Average } \\
\text { costs }\end{array}$} \\
\hline Thyroid uptake & 7964 & $€ 771,249$ \\
Thyroid scan & 48,867 & $€ 4,788,432$ \\
Thyroid ultrasound & 98,103 & $€ 2,320,209$ \\
TSH & $4,034,666$ & $€ 7,213,262$ \\
FT4 & $2,391,604$ & $€ 5,985,205$ \\
FT3 & 764,540 & $€ 1,913,831$ \\
Anti-TPO & 78,881 & $€ 140,035$ \\
Anti-thyroglobuline & 76,312 & $€ 135,470$ \\
Total & & $€ 23,267,693$ \\
\hline
\end{tabular}

TSH, thyroid-stimulating hormone; FT4, free thyroxine; FT3, free triiodothyronine; TPO, thyroid peroxidase.

Source: RIZIV/INAMI.

(€260,000) and social marketing (€10,000), were estimated to be $€ 270,000$ over a $4-5$-year period (Table 4 ).

To calculate the saved costs per year after a 4-year period having the iodization program in place, it was assumed that prevalence of multinodular goiter and thyroid nodules will decrease by $38 \%$ in Belgium as was the case in Denmark with a similar intervention in place (33). The net saved costs per year, due to the optimization of iodine intake in Belgium, can consequently be calculated as follows:

$0.38 \times$ (total TC in the adult population in Belgium) - (total PC including monitoring /5) $=0.38 \times € 37,536,151-€ 270,000 /$ $5=€ 14,209,737$ (Tables 4 and 5).

\section{Discussion}

Our analysis indicates that the saved costs after the implementation of an iodization program in a country suffering from MID can be considerable. In this study in Belgium the net benefit of such a program would be around $€ 14$ million. Nevertheless, these findings have to be interpreted with caution. One of the limitations of this study is that prevalence data from another country were used to perform the calculations. In future, efforts should be undertaken to collect prevalence data on thyroid nodular diseases in Belgium. Further, it needs to be stressed that many costs were not included, such as costs due to better cognition and higher productivity, and costs due to work disability (absence from work), as specified in the methods section, but it makes the estimation reliable and conservative.

It should be noted also that only $1.8 \%$ of the adult persons suffering from thyroid nodules or multinodular goiter are

\section{Table 4. Costs Related to the Iodization} Program in Belgium

\begin{tabular}{lr}
\hline Part of the program & Average costs \\
\hline $\begin{array}{l}\text { National survey in school-aged children } \\
\text { and pregnant women }\end{array}$ & $€ 260,000$ \\
Monitoring of TSH in newborns & 0 \\
Leaflet for pregnant women & $€ 10,000$ \\
Monitoring of iodine content in salt & 0 \\
$\quad$ used for manufacture of bread & \\
Total & $€ 270,000$ \\
\hline
\end{tabular}

Table 5. Summary of Total Average Yearly Costs Related to The Iodization Program AND Thyroid Nodular Diseases in Belgium

\begin{tabular}{lr}
\hline & Average costs \\
\hline Monitoring program & $€ 54,000$ \\
Surgery & $€ 13,128,807$ \\
Treatment (anti-thyroid medication & $€ 1,139,651$ \\
$\quad$ and I-131 therapy) & $€ 23,267,693$ \\
\hline
\end{tabular}

treated with antithyroid medication or I-131 iodine therapy and only $0.33 \%$ undergo surgery. This indicates that a high number of adult persons are probably not aware that they have nodular thyroid disease.

\section{Conclusion}

The yearly costs related to MID in the Belgian adult population are $\sim € 38$ million. It is expected that the iodization program will decrease the prevalence of thyroid nodular disease with $38 \%$ after a $4-5$-year period. Due to this, it will be possible to save at least $€ 14$ million a year.

\section{Acknowledgments}

The authors acknowledge all providers of data used in this study: the Federal Public Service of Health, Food Chain Safety and Environment, the National Institute for Disease and Disability Insurance (RIZIV/INAMI), FARMANET, and IMS.

\section{Disclosure Statement}

The authors declare not having any conflicts of interest. No competing financial interests exist.

\section{References}

1. de Benoist B, McLean E, Andersson M, Rogers L 2008 Iodine deficiency in 2007: global progress since 2003. Food Nutr Bull 29:195-202.

2. Zimmermann MB, Jooste PL, Pandav CS 2008 Iodinedeficiency disorders. Lancet 372:1251-1262.

3. WHO, ICCIDD, UNICEF 2007 Assessment of the Iodine Deficiency Disorders and Monitoring Their Elimination. WHO, Geneva.

4. Delange F, Van Onderbergen A, Shabana W, Vandemeulebroucke E, Vertongen F, Gnat D, Dramaix M 2000 Silent iodine prophylaxis in Western Europe only partly corrects iodine deficiency; the case of Belgium. Eur J Endocrinol 143:189-196.

5. Bourdoux P 1990 Borderline iodine deficiency in Belgium. J Endocrinol Invest 13:77.

6. Ciardelli R, Haumont D, Gnat D, Vertongen F, Delange F 2002 The nutritional iodine supply of Belgian neonates is still insufficient. Eur J Pediatr 161:519-523.

7. World Health Organization, United Nations Children's Fund, International Council for the Control of Iodine Deficiency Disorders 1994 Indicators for Assessing Iodine Deficiency Disorders and Their Control Through Salt Iodization. WHO/NUT/94.6. World Health Organization, Geneva, Switzerland. 
8. Brussaard JH, Brants HA, Hulshof KF, Kistemaker C, Lowik MR 1997 Iodine intake and urinary excretion among adults in the Netherlands. Eur J Clin Nutr 51 Suppl 3:S59-S62.

9. Rasmussen LB, Carle A, Jorgensen T, Knudsen N, Laurberg P, Pedersen IB, Perrild H, Vejbjerg P, Ovesen L 2008 Iodine intake before and after mandatory iodization in Denmark: results from the Danish Investigation of Iodine Intake and Thyroid Diseases (DanThyr) study. Br J Nutr 100:166-173.

10. Rasmussen LB, Ovesen L, Christensen T, Knuthsen P, Larsen EH, Lyhne N, Okholm B, Saxholt E 2007 Iodine content in bread and salt in Denmark after iodization and the influence on iodine intake. Int J Food Sci Nutr 58:231-239.

11. Burgi H, Kohler M, Morselli B 1998 Thyrotoxicosis incidence in Switzerland and benefit of improved iodine supply. Lancet 352:1034.

12. Knudsen N, Bulow I, Jorgensen T, Laurberg P, Ovesen L, Perrild H 2000 Comparative study of thyroid function and types of thyroid dysfunction in two areas in Denmark with slightly different iodine status. Eur J Endocrinol 143: 485-491.

13. Cerqueira C, Knudsen N, Ovesen L, Perrild H, Rasmussen LB, Laurberg P, Jorgensen T 2009 Association of iodine fortification with incident use of antithyroid medication-a Danish Nationwide Study. J Clin Endocrinol Metab 94:24002405.

14. Bulow PI, Laurberg P, Knudsen N, Jorgensen T, Perrild H, Ovesen L, Rasmussen LB 2006 Increase in incidence of hyperthyroidism predominantly occurs in young people after iodine fortification of salt in Denmark. J Clin Endocrinol Metab 91:3830-3834.

15. Vandevijvere S, Van Oyen H 2008 Sodium intake in the Belgian population. Research limitations and policy implications. Arch Public Health 66:187-195.

16. Moreno-Reyes R, Vanderpas J, Neve J, Vandevijvere S, Van Oyen H 2008 A new strategy to optimize iodine intake in Belgium. ICCDD IDD Newsl 29:4-5.

17. Allen L, De Benoist B, Dary O, Hurrell RF 2006 Guidelines on Food Fortification with Micronutrients. World Health Organisation, Geneva.

18. Laurberg P, Nohr SB, Pedersen KM, Hreidarsson AB, Andersen S, Bulow Pedersen I, Knudsen N, Perrild H, Jorgensen T, Ovesen L 2000 Thyroid disorders in mild iodine deficiency. Thyroid 10:951-963.

19. World Health Organization, UNICEF 2007 Iodine Deficiency in Europe: A Continuing Public Health Problem. Andersson M, De Benoist B, Darnton-Hill I, Delange F (eds) World Health Organisation, Geneve.

20. Laurberg P, Cerqueira C, Ovesen L, Rasmussen LB, Perrild H, Andersen S, Pedersen IB, Carle A 2010 Iodine intake as a determinant of thyroid disorders in populations. Best Pract Res Clin Endocrinol Metab 24:13-27.

21. Koutras DA, Alexander WD, Buchanan WW, Crooks J, Wayne EJ 1960 Stable iodine metabolism in non-toxic goitre. Lancet 2:784-787.

22. Glinoer D, Lemone M 1992 Goiter and pregnancy: a new insight into an old problem. Thyroid 2:65-70.

23. Baltisberger BL, Minder CE, Burgi H 1995 Decrease of incidence of toxic nodular goitre in a region of Switzerland after full correction of mild iodine deficiency. Eur J Endocrinol 132:546-549.

24. Gordon RC, Rose MC, Skeaff SA, Gray AR, Morgan KM, Ruffman T 2009 Iodine supplementation improves cognition in mildly iodine-deficient children. Am J Clin Nutr 90: 1264-1271.

25. Delange F 2000 The role of iodine in brain development. Proc Nutr Soc 59:75-79.

26. Delange F 2001 Iodine deficiency as a cause of brain damage Postgrad Med J 77:217-220.

27. Vermiglio F, Lo Presti VP, Moleti M, Sidoti M, Tortorella G, Scaffidi G, Castagna MG, Mattina F, Violi MA, Crisa A, Artemisia A, Trimarchi F 2004 Attention deficit and hyperactivity disorders in the offspring of mothers exposed to mild-moderate iodine deficiency: a possible novel iodine deficiency disorder in developed countries. J Clin Endocrinol Metab 89:6054-6060.

28. Zimmermann MB 2009 Iodine deficiency in pregnancy and the effects of maternal iodine supplementation on the offspring: a review. Am J Clin Nutr 89:668S-672S.

29. Pedersen IB, Laurberg P, Knudsen N, Jorgensen T, Perrild H, Ovesen L, Rasmussen LB 2007 An increased incidence of overt hypothyroidism after iodine fortification of salt in Denmark: a prospective population study. J Clin Endocrinol Metab 92:3122-3127.

30. Laurberg P, Pedersen KM, Hreidarsson A, Sigfusson N, Iversen E, Knudsen PR 1998 Iodine intake and the pattern of thyroid disorders: a comparative epidemiological study of thyroid abnormalities in the elderly in Iceland and in Jutland, Denmark. J Clin Endocrinol Metab 83:765-769.

31. Bulow PI, Knudsen N, Jorgensen T, Perrild H, Ovesen L, Laurberg P 2002 Large differences in incidences of overt hyper- and hypothyroidism associated with a small difference in iodine intake: a prospective comparative registerbased population survey. J Clin Endocrinol Metab 87:44624469.

32. Szabolcs I, Podoba J, Feldkamp J, Dohan O, Farkas I, Sajgo M, Takats KI, Goth M, Kovacs L, Kressinszky K, Hnilica P, Szilagyi G 1997 Comparative screening for thyroid disorders in old age in areas of iodine deficiency, long-term iodine prophylaxis and abundant iodine intake. Clin Endocrinol (Oxf) 47:87-92.

33. Vejbjerg $\mathrm{P}$, Knudsen $\mathrm{N}$, Perrild $\mathrm{H}$, Carle A, Laurberg $\mathrm{P}$, Pedersen IB, Rasmussen LB, Ovesen L, Jorgensen T 2007 Effect of a mandatory iodization program on thyroid gland volume based on individuals' age, gender, and preceding severity of dietary iodine deficiency: a prospective, population-based study. J Clin Endocrinol Metab 92:1397-1401.

34. Laurberg P, Pedersen KM, Vestergaard H, Sigurdsson G 1991 High incidence of multinodular toxic goitre in the elderly population in a low iodine intake area vs. high incidence of Graves' disease in the young in a high iodine intake area: comparative surveys of thyrotoxicosis epidemiology in East-Jutland Denmark and Iceland. J Intern Med 229:415-420.

Address correspondence to: Stefanie Vandevijuere, M.Sc. Unit of Epidemiology Scientific Institute of Public Health J. Wytsmanstraat 14 Brussels 1050 Belgium E-mail: stefanie.vandevijvere@wiv-isp.be 